\title{
ARQUITECTURA RURAL MENOR EN MAGALLANES I
}

MATEO MARTINIC B." Y SAMUEL GARCIA O."*

\section{RESUMEN}

En lo referido a la arquitectura rural en Patagonia y Tierra del Fuego, estudios previos han considerado los grandes cascos de estancias, esto es, galpones, casa administración, emplazamiento etc., todo ello correspondiente a una arquitectura rural de escala mayor. De forma simultánea ha existido una arquitectura rural de menores dimensiones que ha permanecido inadvertida en los estudios arquitectónicos y históricos realizados hasta entonces. El artículo expone un primer caso de arquitectura rural menor, conocida popularmente como la "caravana" o "puesto rodante"1.

PALABRAS CLAVE: arquitectura, rural, Patagonia, ganadería ovina.

\section{MINOR RURAL ARCHITECTURE IN MAGALLANES}

\begin{abstract}
Regarding rural architecture in Patagonia and Tierra del Fuego, previous studies have considered big hulls of estancias or ranches, that is: storehouses, administration, emplacement, etc., all in relation to rural architecture of a macro scale. Simultaneously, rural architecture of minor dimensions has existed but ignored by the architectural and historical studies till now. This article exposes a first case of minor rural architectural, known popularly as caravans, "caravana" or "puesto rodante".

KEY WORDS: architecture, rural, Patagonia, sheep farming.

\section{INTRODUCCIÓN}

El interés por las formas edificadas disponibles en el extenso ámbito patagónico y

fueguino tanto chileno como argentino es de época reciente y sobre la materia se han ocupado profesionales de la arquitectura e historiadores, unos y otros en la común valorización de lo que

- Profesor Titular y Emérito, investigador Centro de Estudios del Hombre Austral, Instituto de la Patagonia, Universidad de Magallanes.mateo.martinic@umag.cl.

* Arquitecto y Licenciado en Arquitectura. Investigador asociado al Centro de Estudios del Hombre Austral, Instituto de la Patagonia, Universidad de Magallanes. samuelgarciaoteiza@gmail.com.

1 Proyecto PY-F3-01CEH A-12. Dirección de Investigación, Universidad de Magallanes.
\end{abstract}


las mismas caracterizan, esto es, la adaptación del hombre al territorio (en sus diferentes variantes geográficas y ambientales), circunstancia expresada en tipologías, modos de construir, materiales y uso dado a las mismas. Del conjunto hasta ahora conocido de comunicaciones sobre el tema (libros, artículos, tesis de grado), escaso en numero por lo demás, una parte está referida a las edificaciones urbanas y otra a las del ámbito rural. Tocante a este aspecto, el primero de los autores participó años atrás en un proyecto de investigación dirigido por el arquitecto Juan Benavides y que concluyó con la primera publicación conocida sobre la materia, Las estancias magallanicas (Ediciones de la Universidad de Chile, Santiago 1999). En la misma se aborda la forma constructiva originada en el contexto de la crianza ovina extensiva y desarrollada según sus necesidades, en un patrón tipológico común para los territorios donde la misma se estableció como actividad productiva determinante, esto es, en lo que interesa, en el amplio espacio patagónico chileno-argentino (incluido el fueguino), ciñéndose, debe destacarse, a las formas edificadas originadas en los países desde donde se introdujo la actividad (Escocia, Islas Malvinas o Falkland) o desde las que recibió influencia tecnológica para su desarrollo (Australia, Nueva Zelandia).

Las formas de interés y estudio fueron las tenidas por principales o determinantes en la actividad productiva ovejera extensiva: galpones de esquila, bodegas, talleres y oficinas; viviendas patronales, habitaciones de trabajadores, comedores y cocinas, del mismo modo que su disposición y ordenamiento espacial aprovechando las características del terreno más favorables para el objeto (reparo del viento, disponibilidad de agua, facilidad de acceso y otros).

Dándose por sobreentendido el hecho de la exigencia de otras edificaciones e instalaciones menores, de cualquier manera necesarias para la actividad productiva, hasta ahora no se ha realizado un estudio complementario sobre las mismas para identificarlas y caracterizarlas tipológicamente. Su necesidad, por ello nos parece obvia, pues sólo así se podrá disponer de una visión integral de lo que históricamente ha conformado la crianza ovina,

2 Una presentación preliminar sobre la materia bajo el título Arquitectura Rural Menor. Un rasgo distinto para comprender el paisaje cultural en la estepa austral", fue hecha por el según se la ha conocido y conoce por su expresión física caracterizadora: la estancia (magallánica, patagónica) atendido los requerimientos de vida y trabajo que les son propias.

A la singularidad de sus instalaciones que la definen, más cuando asumen la condición de exclusivas de la actividad pastoril extensiva, se ha añadido su apreciación como elementos tangibles del patrimonio histórico de las correspondientes regiones, en tanto que son representativas de una cultura rural caracterizadora, y como tales merecedoras de conocimiento y protección como bienes expresivos de estilos de vida y trabajo ${ }^{2}$.

\section{CONCEPTO}

Entendemos por "Arquitectura rural menor" la correspondiente a la forma de pensar la realidad a través del diseño de construcciones de variado tipo que conforman, por lo común, un complemento de aquellas edificaciones de mayor jerarquía visibles en el ámbito rural por razón de proporciones, tamaño y funciones que requieren necesariamente de conocimientos específicos por su complejidad en lo tocante a diseño y construcción y que se manifiestan comúnmente en planos; en buenas cuentas, formas sencillas cuya vigencia (materialidad) no puede concebirse como expresiones autónomas, sino necesaria y funcionalmente dependientes de edificaciones de mayor jerarquía o importancia (viviendas o centros de trabajo), sin embargo de lo cual y en su repetición temporal ha llegado a definir, inclusive un cierto estilo caracterizador. Vistas y entendidas así, las mismas tanto contribuyen a una mejor y más completa información acerca de lo que ha sido, y todavía es, la materialidad edificada del ámbito rural productivo en lo tocante a la vida campesina, cuanto integran el patrimonio cultural tangible de la Región Magallánica.

\section{TIPOLOGÍA}

\section{a) Habitabilidad ocasional}

1. Caravana

2. Refugio de ovejeros (arrieros)

b) Utilitaria

primero de los autores en "Paisajes Culturales. Jornadas de reflexión sobre los paisajes culturales de Argentina y Chile", Río Gallegos 13-15 de junio de 2012. 
1. Cochera (garage)

2. Leñera

3 .Carnicería

4. Papera ("sotano")

5. Caseta motor luz

6. Otros

c) Cobijo animal

1. Caballeriza (pesebrera)

2. Perrera

3. Chanchera (porqueriza)

4. Gallinero

5. Palomar

d) Otras funciones de servicio

1. Torre del agua potable

2. W. C.

3. Estanques australianos techados

4. Otros

e) Formas complementarias

1. Cercos de ornato

2. Cortavientos

3. Corrales y mangas

4. Cargaderos

5. Escalera para cruzar alambrados

\section{LA CARAVANA, PRIMER CASO DE ESTUDIO}

A comienzos del siglo XX las extensas pampas patagónicas y fueguinas se convirtieron en el lugar idóneo para llevar a cabo el inicio de la explotación pastoril y por lo tanto de alguna forma había que controlar su extensión o condición de infinitud. De a poco las extensas pampas fueron perdiendo la condición de espacio inhóspito en el imaginario del hombre foráneo. Fueron apareciendo los cercos y alambrados, simultáneamente surgirían los establecimientos explotadores y cascos de estancias, sin embargo faltaba una solución, un anexo de la estancia para controlar y resguardar el ganado ovino disperso por las extensas planicies durante los distintos meses del año.

En efecto, el desarrollo de la modalidad de crianza extensiva de ovinos como opción convenientemente rentable quedó tempranamente probado en la historia económica patagónica y más aún a partir de 1902-1910, cuando se impuso la forma de tenencia latifundiaria que cimentaría la fama productiva de los campos australes y su determinante contribución al desarrollo general de la región meridional del continente americano.
Entonces en un sistema de explotación que concentraba los centros de vida y trabajo en núcleos edificados, cascos de estancias, el resto del espacio territorial ocupado se utilizaba para el pastoreo trashumante del ganado de acuerdo con la división convencional de carácter práctico en fracciones mayores y menores (campos de invernada o veranada, potreros). Ello significaba que en tal manejo económico la presencia humana en los espacios más extensos se correspondía con la de ovinos para fines de vigilancia, lo que incluía la correspondiente movilidad laboral o, lo que es igual, la transitoriedad o temporalidad habitacional, limitada solo al lapso de permanencia (semana o meses) estimado necesario en el contexto del manejo operativo.

En estos casos la administración de las grandes estancias aconsejaba edificar viviendas (puestos) de carácter permanente únicamente en los lugares más importantes para la actividad criadora del establecimiento, dejando para otros campos vastos o distantes la modalidad de una vivienda transportable, esto es, la conformada por un espacio habitable mínimo montado sobre ruedas, que fue la solución ideal encontrada para ese requerimiento.La forma eficaz del control de los animales sería moverse con ellos por las extensas planicies, ello llevaría a un modo de pensar la realidad por medio de la arquitectura.

La solución de control de esta realidad fue importada desde Europa, donde era denominada sleeping o living van. La condición de puesto rodante le permitiría desplazarse según los requerimientos específicos y de esta forma se estableció una lógica y estrategia de ocupación territorial a modo de mueble o objeto que se posa sobre un soporte físico determinado, sustrayéndose del entorno físico y sin arraigo por el territorio al no establecer una relación directa con el suelo, sino más bien despegado de él, en el caso particular del puesto rodante, sobre-puesto por medio de ruedas.

Así el puesto rodante fue el resultado de una forma de pensar el dominio de un territorio estepario traducido en un habitar en movimiento. Esta condición de movilidad y temporalidad no les permitió a diferencias de otras soluciones habitacionales, como por ejemplo lo fueron los puestos y ranchos, el convertirse para el habitante en un referente espacial. 

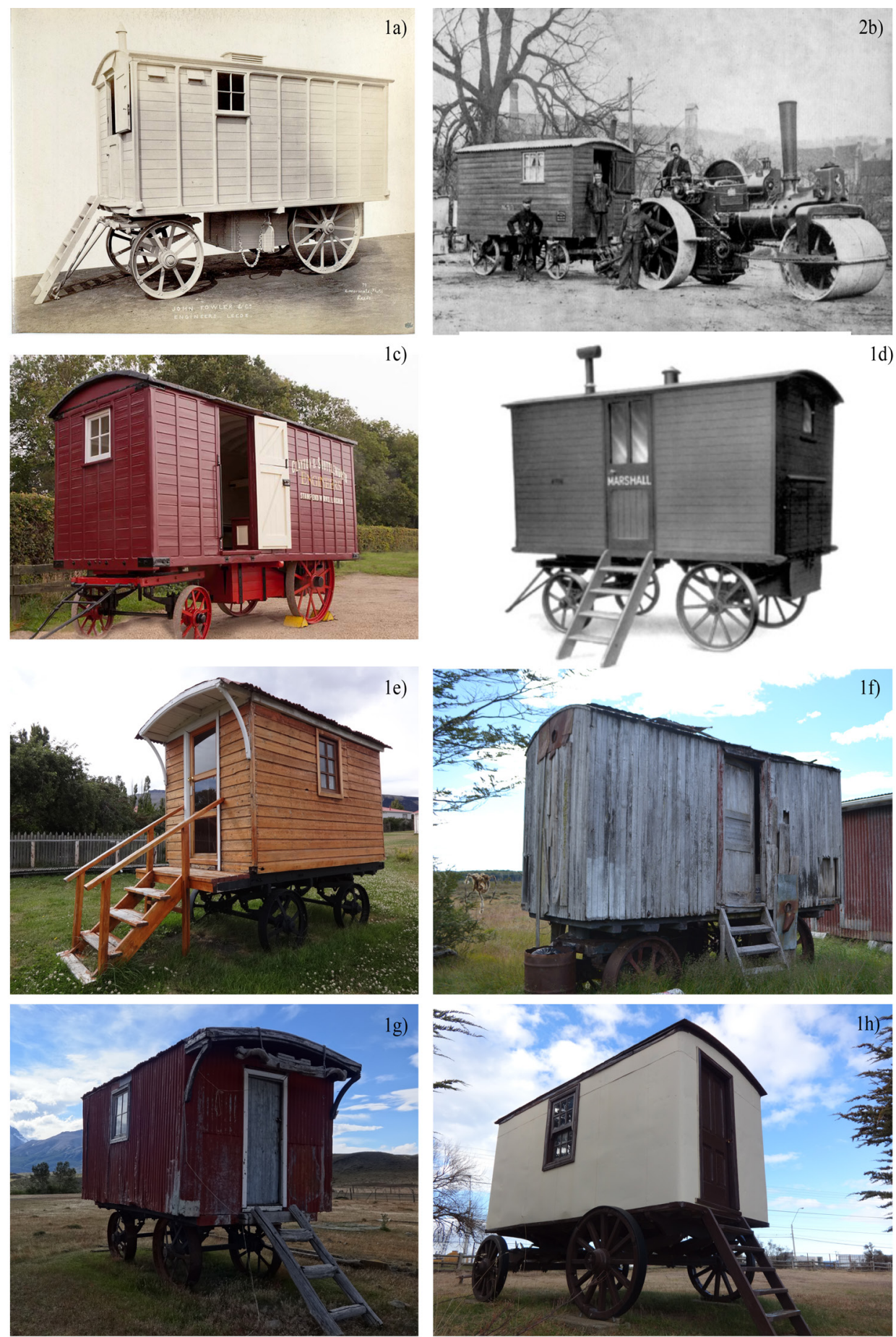

Fig. 1a) Living Van de la firma John Fowler Co (Leeds). 1b) Arrastre de una living van de la firma Aveling \& Porter (1895). 1c) Exhibición de una Living Van de la firma Clayton \& Shuttleworth, Londres. 1d) Living Van exhibida en un catálogo de la firma Marshall Sons. 1e) Caravana de la firma $J$ \& H. McLaren ubicada en estancia "Cerro Guido". 1f) Caravana de la firma John Fowler Co. ubicada a un costado del puesto "Zapata", estancia "Cameron" (Foto Nicolás Recabarren T. 2014). 1g) Caravana de la firma J \& H. McLaren ubicada en estancia "Laguna Amarga". 1h) Caravana ubicada en el Museo del Recuerdo. 

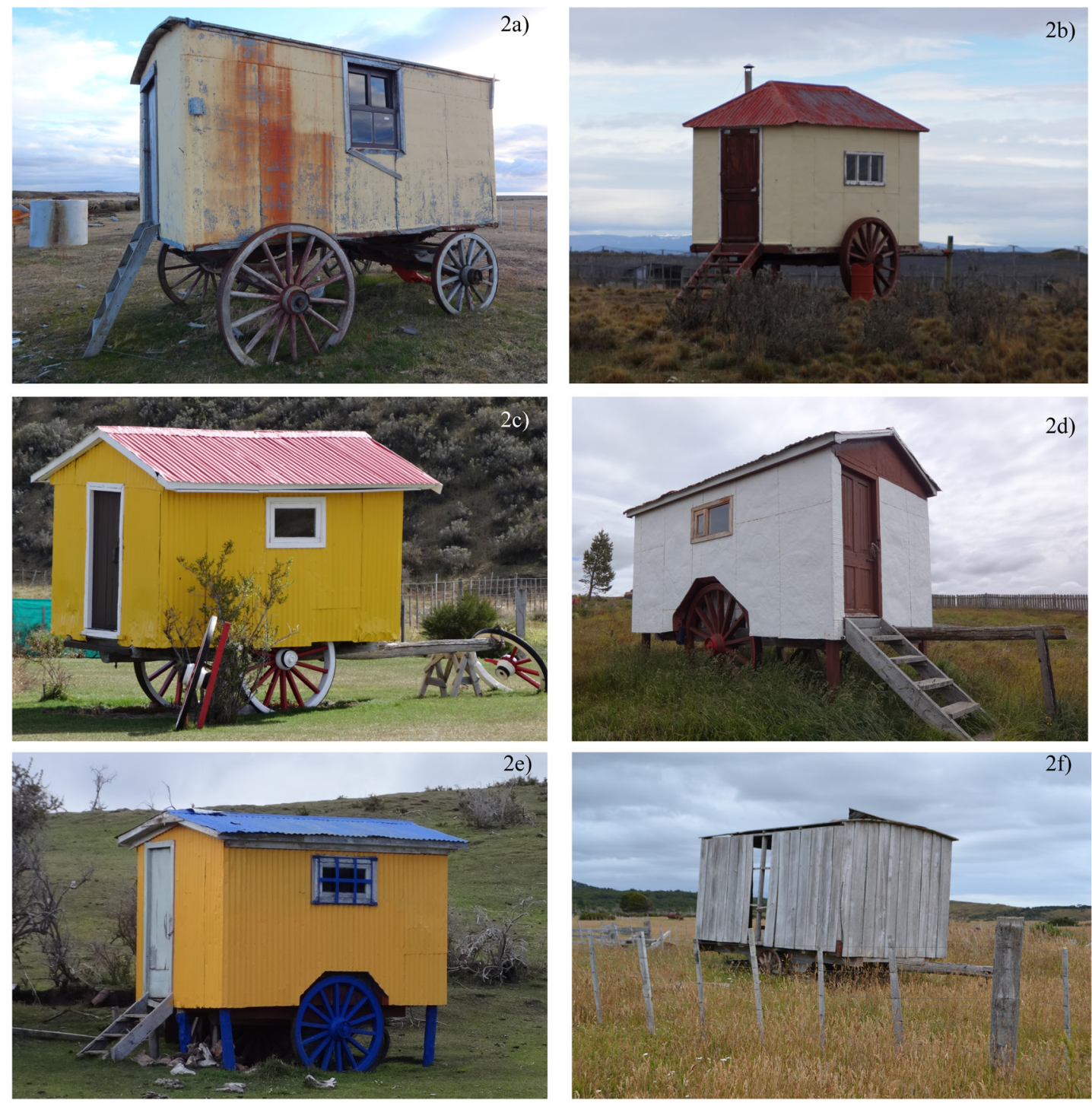

2g)
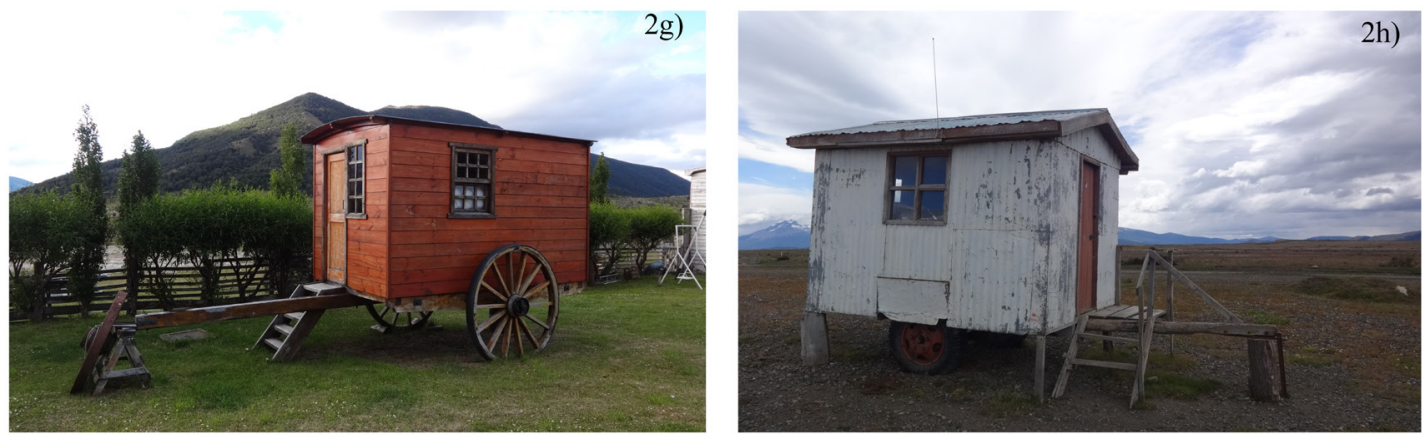

Fig. 2a) Caravana ubicada en estancia "Guayrabo". 2b) Caravana ubicada en estancia "Lolita", correspondiente a la tipología de dos ruedas. 2c) Caravana ubicada en el "Chalet", Porvenir. 2d) Caravana ubicada en estancia el "Morro". 2e) Caravana ubicada en estancia "Rosario", Tierra del Fuego. 2f) Caravana de dos ruedas ubicada en Puerto Yartou, (foto Macarena Fernández G. 2014). 2g) Caravana ubicada en hostería "Tres Pasos"(construida con fines turísticos). 2h) Caravana con neumáticos ubicada en estancia "Dos Lagunas". 


\section{UNA APROXIMACIÓN AL ORIGEN DE LA CARAVANA EN MAGALLANES}

Asociada en el imaginario popular con los característicos carromatos de gitanos descritos en obras literarias y vistos en películas, la "caravana", en la denominación tradicional del campo magallánico, es quizás el único tipo de edificación menor de origen foráneo directamente incorporado al uso rural y con antigua naturalización territorial. En efecto, si bien es un elemento de temprano empleo en la actividad criadora ovejera, no se sabe con certidumbre si el mismo tuvo ocurrencia por razón de la adopción de un modelo disponible en el mercado europeo, probablemente en el británico, $\mathrm{o}$, si fue fabricado localmente copiándoselo de piezas foráneas. De partida, en cualquiera de las alternativas, no debería ponerse en duda que el tipo original o prototipo del genero arquitectónico en consideración fuera la sleeping o living van fabricadas por firmas inglesas, entre ellas; Aveling \& Porter, Eddison Vans, Clayton \& Shuttleworth, John Fowler, Eddison Rolling, Doran Bros, Marshall, Sons, J \& H. McLaren (ver fig. 1a-1g).

En la primera alternativa, mencionada más arriba, su confirmación sólo podría darse con el hallazgo de documentos (cartas de pedido o despacho, facturas) que así lo confirmaran, pero es bien sabido que ello es muy difícil por razón de las escasa disponibilidad de papeles mercantiles de época (fines del siglo XIX, principios del $\mathrm{XX)}$, restando únicamente la posibilidad de observación de placas de fabricación identificatorias, cosa no siempre posible por ser estas elementos que suelen sustraerse de antiguas piezas de uso industrial. Para efectos de esta investigación se pudieron catastrar tres caravanas con placas de identificación que detallan el lugar origen y nombre de la firma fabricante. Dos de estas caravanas pertenecen a la firma $J \& H$. McLaren (ver fig. 1e,1g), y se ubican actualmente en la estancia "Laguna Amarga" y "Cerro Guido", provincia de Última Esperanza. La tercera caravana de la firma John Fowler $^{3}$ (ver fig. 1f) se ubica en el sector del

3 Agradecemos a Nicolás Recabarren T. y a Macarena Fernández $\mathrm{G}$. facilitarnos generosamente este antecedente recogido por ellos durante una salida a terreno en febrero del 2014. puesto "Zapata", terrenos pertenecientes a la estancia "Cameron", provincia de Tierra del Fuego. Estas tres caravanas fueron fabricadas en la ciudad inglesa de Leeds.

No hay duda que estas tres caravanas mencionadas, de las marcas $J \& H$ McLaren y John Fowler fueron introducidas por la Sociedad Explotadora Tierra del Fuego, propietaria y/o concesionaria a inicios del siglo XX, de los terrenos donde se encuentran actualmente las caravanas en consideración.

Respecto a la segunda alternativa, si la caravana fue fabricada localmente copiándose de piezas foráneas, se catastraron otras tres caravanas que no cabe duda que por lo elemental de su estructura soportante en madera y de solo dos ruedas, son de fabricación local y se podría estimar que en su diseño se pudo haber utilizado como referente la caravana de origen inglesa o un tipo existente en la región, sin placa identificatoria y que aparentemente pertenecían a la Sociedad Explotadora Tierra del Fuego, cuyas piezas estructurales de madera fueron fabricadas en serie (ver más adelante en tipologías).

Como haya sido, esta vivienda móvil, expresión característica de arquitectura menor, se incorporó la manejo pastoril sudpatagónico desde una época muy temprana, con seguridad al principio del siglo XX.

Debe señalarse que en la alternativa probable de fabricación local, copiándose o adaptándose algún modelo foráneo, tal capacidad industrial pudo ser brindada a cabalidad por los establecimientos de carrocería que funcionaban en Punta Arenas desde las postrimerías del siglo XIX, que proveyeron durante medio siglo a lo menos a la actividad criadora ovejera de elementos de transporte pesado (carros y carretas) de diversas clase. El diseño arquitectónico de las piezas antiguas que se preservan hasta nuestros días, en especial en lo que se refiere a la tipología de puertas y ventanas, aquellas de tableros en cruz y estas de ocho a doce vidrios en dos hojas, una fija y otra movible (guillotina), evidencia su íntimo parentesco, si no su procedencia de las correspondientes formas empleadas en las viviendas del denominado "estilo

4 Descripción hecha a la vista de la caravana que se exhibe en el Museo del Recuerdo, Instituto de la Patagonia, Universidad de Magallanes. 
pionero", lo que sugiere una noción tradicional de carpintería artesanal.

El catastro de las formas del género que se mantienen en las estancias actuales y en el Museo del Recuerdo (Instituto de la Patagonia, Universidad de Magallanes) da cuenta del mantenimiento original o antiguo, conjuntamente con formas evolucionadas en lo tocante a sus diversos componentes (ruedas, puertas, ventanas y techumbre principalmente), correspondiente $\mathrm{y}$, mejor aun, en la planimetría diferenciada de los tipos antiguo y moderno.

En síntesis, consideramos a la descrita como la forma más característica de la arquitectura rural menor sudpatagónica, en tanto que es una construcción utilitaria para habitación cuya bondad de uso ha quedado más que probada por su prolongada vigencia histórica en la ganadería ovina, que supera el siglo, con el añadido indudable de su valor patrimonial histórico como referente auténtico de un aspecto de la vida rural, en especial el propio de los ovejeros.

\section{EL ESPACIO INTERIOR DE LA CARAVANA}

Destinada a servir de vivienda temporal, el espacio habitable de la caravana era reducido, pensada para ser habitada por una o dos personas, y la distribución de los sectores de uso estaban claramente determinados. La condición de un habitar de tiempo determinado y para ser ocupada por un numero definido de habitantes ayuda a explicar la solución y expresión formal de la caravana.

La planta de la caravana es rectangular y de un ambiente interior, condicionando los actos del puestero a un habitar precario que responde meramente a lo funcional, obviando otras necesidades como las psicológicas y emocionales y aun más, sin grados de intimidad o privacidad para el caso de puestos rodantes para dos hombres. En su interior existe una distribución lógica de objetos que dan orden al interior. De partida, al fondo del recinto se hallaba uno (o dos) camarotes, camas fijas adosadas a las paredes, para descansar y dormir; hacia la entrada y en proximidad a la puerta de acceso se instalaba una estufa a carbón y leña (cocina), de fierro fundido y pequeño tamaño, aunque suficiente para calefaccionar el reducido

\footnotetext{
La planta de la caravana $J \& H$. McLaren que se emplaza actualmente en la estancia "Laguna Amarga", ha sido modificada, siendo ampliada $35 \mathrm{~cm}$. hacia cada uno de sus
}

ambiente y permitir la cocción de alimentos; el escaso mobiliario se completaba con un cajón rectangular inmediato situado bajo una de las ventanas, que servía para guardar las provisiones y como asiento para el ovejero ocupante; al frente, por fin y bajo la otra ventana se ubicaba una suerte de mesa en repisa para comer $^{4}$ (ver fig. 3a, 4a).

En fin, en su interior todo se resume a las necesidades biológicas básicas; dormir y alimentarse, sin considerar, por ejemplo, el aseo y higiene personal. La separación de ambientes está dada, de forma virtual, por el mobiliario elemental, cocina, mesa y cama; la proporción y dimensionamiento del espacio parece aceptable y ajustada a los movimientos como resultado de la relación funcional hombre-objeto. Cabe señalar que los vanos, en los casos estudiados, por su ubicación, dividen dos instancias en el interior del puesto, el área de descanso, servicios y acceso.

En cuanto a la relación interior-exterior no existe un espacio intermedio que construya una instancia entre un estar dentro y fuera, algo necesario considerando el clima riguroso de la región. En este sentido, la escalera devela el acceso y asume un rol de umbral, construye un tiempo de traspaso entre el interior y el exterior, sustrayendo al puesto del suelo, para dar paso al espacio-habitación. Sin embargo no logra construir ese espacio preámbulo, real y necesario en donde el puestero, por ejemplo, pueda dejar la ropa de trabajo sucia con barro o mojada, las botas, los aperos y herramientas, etc. Los vanos adquieren gran importancia en la medida que establecen una relación visual entre el interior y exterior, lo que permite al puestero controlar visualmente y a la distancia su objetivo, además de proporcionar, la siempre necesaria luz natural al interior del puesto.

\section{TIPOLOGÍAS DE CARAVANAS}

A la vista de las caravanas que se registraron, se pudo determinar tres tipos presentes en la región. A continuación se presenta una descripción de las tipologías catastradas.

\section{a. Modelo inglés}

Corresponde a la que sin duda es el prototipo

costados transversales, también se ha reemplazado su revestimiento original de madera por planchas de zinc acanalado. 


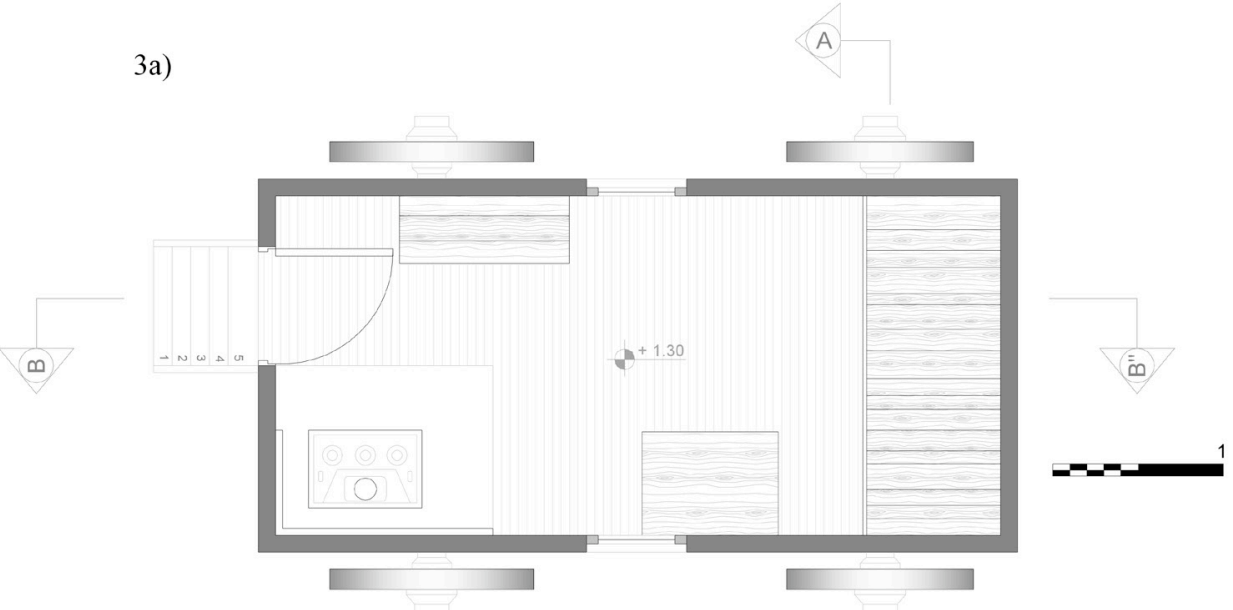

3b)



3e) 3c)

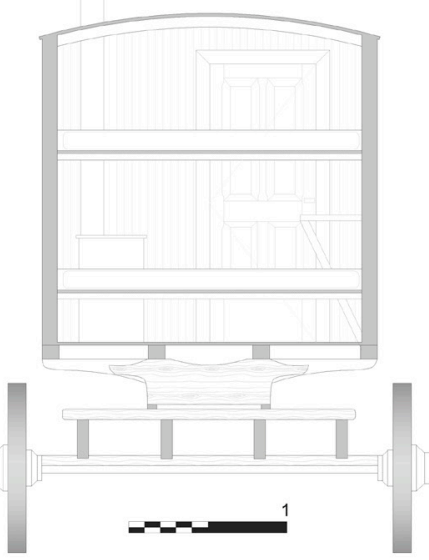

3f)

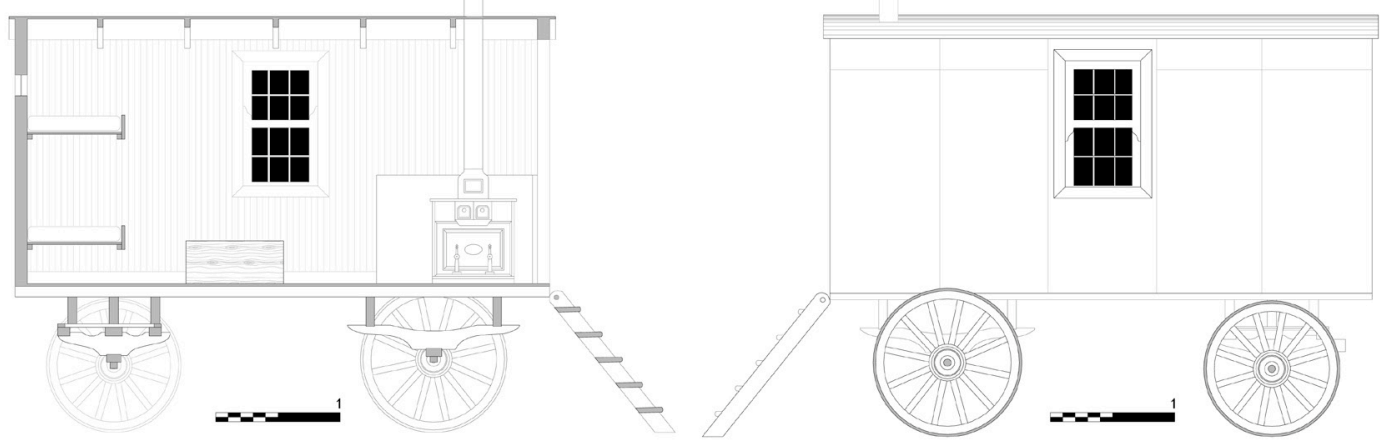

Fig. 3a) Planta de caravana tipología B. 3b) Elevación de acceso. 3c) Corte A-A'. 3d) Elevación posterior. 3f) Corte B-B' de caravana tipología B. 3g) Elevación longitudinal. (dibujos Samuel García O.) 


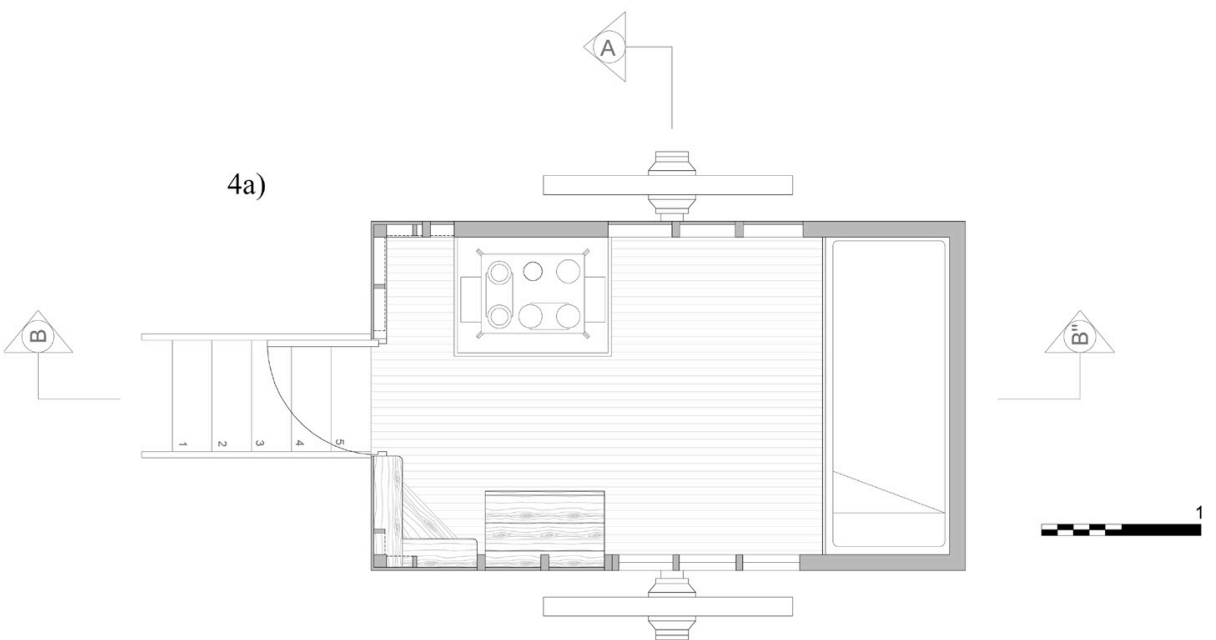

4b)



4e)

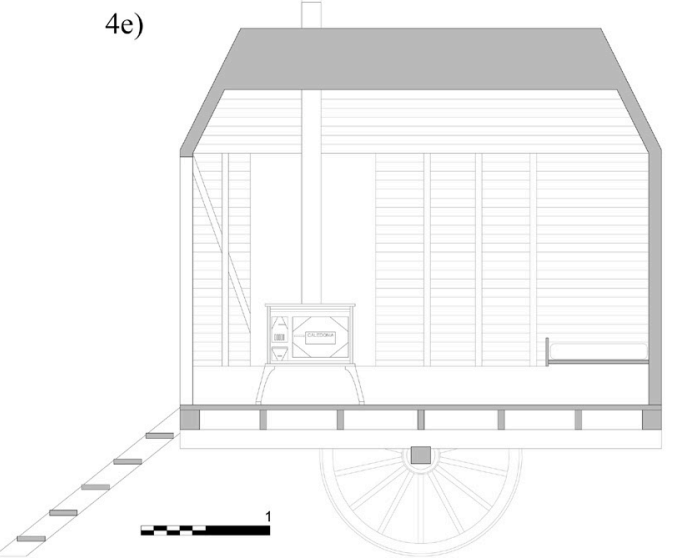

4f)

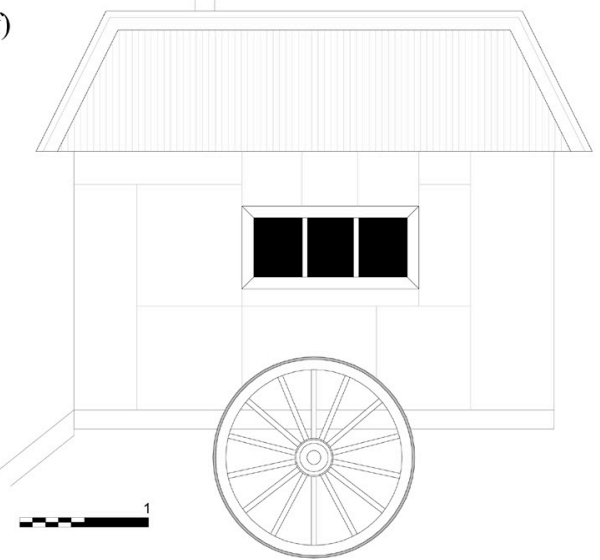

4c)
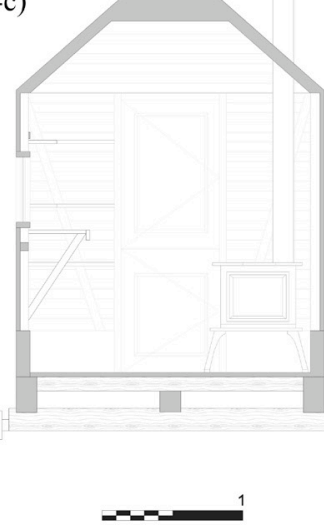

4d)

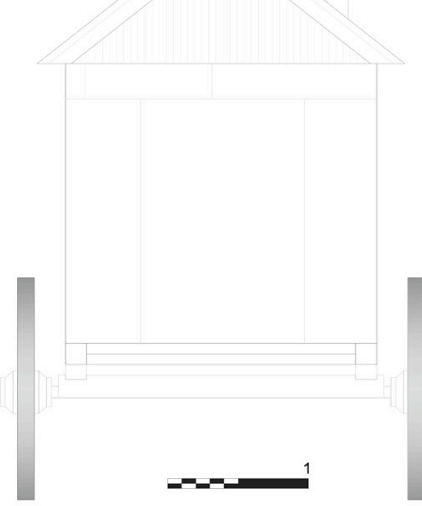

Fig. 4a) Planta caravana estancia "Lolita". 4b) Elevación acceso. Fig. 4c) Corte A-A'..4d) Elevación posterior. 4e) Corte B-B'. 4f) Elevación longitudinal (dibujos Samuel García O.). 
original conocida como la living o sleeping van, como se mencionó anteriormente, fabricado por las firmas John Fowler y $J \& H$. McLaren en la ciudad inglesa de Leeds (ver fig. 1e, 1f, 1g). La estructura soportante es de acero, esto es amortiguadores, ejes, ruedas y sus respectivos rayos, la estructura secundaria son vigas de madera que conforman un entramado debidamente diseñado sobre el cual se asientan cinco vigas maestras de madera de 4"x 6" y sobre estas el entablado machihembrado de madera de 3" empleado para el piso interior y el cielo falso de la caravana, ambos revestimientos, cielo y suelo, van colocados en el sentido longitudinal de la caravana. Su estructura de techumbre son siete vigas de maderas a la vista de $1 \frac{1 / 2}{2}$ x 3 ", con una leve curvatura, conformando las caídas de agua del exterior de la caravana, el revestimiento exterior de la cubierta es de planchas de zinc acanalada. Posee cuatro ruedas, de $90 \mathrm{~cm}$. de diámetro correspondiente a las ruedas del tren delantero y de $80 \mathrm{~cm}$. de diámetro para las ruedas del tren trasero, su ancho es de $15 \mathrm{~cm}$. y el de sus rayos $7 \mathrm{~cm}$ remachados a la rueda. El tren delantero está unido mediante dos argolla superpuestas de acero de 85 $\mathrm{cm}$. de diámetro por $6 \mathrm{~cm}$. de ancho, las cuales van unidas a la pértiga de tiro permitiendo mayor direccionalidad y flexibilidad a los movimientos que requiera la caravana. La planta de la caravana es de 3.67 x 2.02 mts. $\left(7.4 \mathrm{~m}^{2}\right)^{5}$.

Respecto al revestimiento exterior de la caravana de la firma $J \& H$. McLaren, el mismo es de tablas de madera de 5" colocadas horizontalmente. El modelo incluye un alero de $50 \mathrm{~cm}$. en el acceso y dos placas ovaladas de $15 \times 9 \mathrm{~cm}$ con el inscripción $J \& H$. McLaren Leeds Engineers ubicadas en el extremo de las vigas maestras perimetrales. $\mathrm{Su}$ pértiga de tiro es una pieza metálica de 15 x 150 $\mathrm{cm}$. A diferencia de la caravana de la firma $J \& H$. McLaren, la caravana de John Fowler posee su inscripción en el eje de la rueda John Fowler \& Co (Leeds) Ltd., tiene una ventana fija de $60 \mathrm{~cm} \times 60$ $\mathrm{cm}$ con tablero en cruz de cuatro vidrios, ubicada en una de sus fachadas transversales. Esta caravana tiene el acceso ubicado en la fachada longitudinal, siendo la única en su tipo de las que se pudieron catastrar; su revestimiento exterior es de tablas de madera de 3" colocadas en sentido vertical. Para ambos casos de caravanas, la escalera de acceso

\footnotetext{
6 Agradecemos nuevamente a Nicolás Recabarren T. y a Ma-
}

han sido modificada, lo que no permite conocer el y diseño original de cada una, lo mismo sucede con las ventanas de la caravana de $J \& H$. McLaren.

\section{b. Con piezas de madera fabricadas en serie}

Son aquellas caravanas con un interesante diseño de piezas estructurales soportante fabricadas en serie. Aparentemente estos puestos rodantes pertenecían a la Sociedad Explotadora Tierra del Fuego y se desconoce si su fabricación fue local o introducida a la región de Magallanes, ya sea completa o por partes con su correspondiente planimetría y fue luego armada en la región (ver fig. 1h, 2a, 3a-3f). Se pudo catastrar cuatro caravanas de este tipo, dos en la estancia "Guayrabo", que fueron traídas de la estancia Cameron, Tierra del Fuego (Chile). Otras dos se encuentran en el Museo del Recuerdo del Instituto de la Patagonia.

$\mathrm{Su}$ sistema estructural soportante se compone de vigas de madera de distintas dimensiones y plástica, con un diseño formal interesante y original donde los extremos de la viga son de menor dimensión y va en aumento hacia centro para recibir y distribuir, de forma eficiente, las cargas a las que se ve sometida la estructura. Posee cuatro ruedas de madera de $110 \mathrm{~cm}$ y 120 $\mathrm{cm}$ de diámetro, con aros de hierro; las primeras están ubicadas en el tren delantero y las segunda en el tren trasero. Al igual que el modelo inglés posee un eje rotatorio unido a la pértiga de tiro. La dimensión de la planta es de 4.27 x 2.00 mts. (8.54 m2) y la altura interior es de $2.17 \mathrm{mts} .2$.

Sobre la estructura soportante se apoyan cuatro vigas maestras de 3" $1 / 2 \times 4$ x y sobre estas el piso machiembrado de 3". La estructura de techumbre esta conformada por 5 vigas de madera a la vista, levemente curvadas de $1 \frac{1}{2}$ " $\mathrm{x}$ 3" y distanciadas entre ellas a $70 \mathrm{~cm}$ a eje. Los pies derechos de los tabiques perimetrales son de 3" x 3". El diseño de la caravana consideró dos ventanas guillotina de 102 x $61 \mathrm{~cm}$ con una hoja fija de y otra movible, ambas de $54 \times 61 \mathrm{~cm}$, con seis vidrios cada una y un antepecho de $80 \mathrm{~cm}$ También se incluyó una ventana fija de menor dimensión de $50 \times 17 \mathrm{~cm}$, con un antepecho de $153 \mathrm{~cm}$ ubicada en la parte superior del camarote. Los muros interiores están revestidos en tablas de madera de 3" y los exteriores en planchas de zinc

carena Fernández G. facilitarnos este antecedente. 
liso al igual que la cubierta. La escalera de acceso esta fijada a la caravana mediante un eje rotatorio de acero, lo que permite que se pliegue cuando la caravana se desplaza.

\section{c. Con variación local de dos ruedas}

Se pudieron catastrar al menos cinco caravanas de esta tipología. La principal característica de ella es que tiene sólo dos ruedas en vez de cuatro, las vigas maestras van apoyadas directamente en una viga que une los dos ejes de las ruedas y el modelo no incluye un eje rotario unido a la pértiga de tiro. Las caravanas catastradas están ubicadas en los campos de la estancia "Lolita", "El Morro", "Rosario", Puerto Yartou 6 y en Porvenir, en el lugar conocido como el "Chalet" camino a bahía Chilota, estas tres últimas en Tierra del Fuego (ver fig. 2b-2h). La expresión formal de cada una de la caravanas catastradas se diferencia en pequeños detalles, ya sea en tamaño de la planta, materialidad de revestimiento interior y exterior (zinc liso, acanalado o madera), volumetría de cubierta (a una, dos y cuatro aguas), ventanas (fijas, batientes, guillotina, con tablero cruz de cuatro vidrios), puertas de dos hojas verticales etc. Las ruedas son de madera y aro de hierrro, y tienen de ancho $15 \mathrm{~cm}$ y $160 \mathrm{~cm}$ de diámetro, excepción hecha de la caravana ubicada en puerto Yartou que es de diámetro inferior. En algunos casos como las caravanas de "El Morro" y "Rosario", las ruedas quedan integradas en el espesor del tabique y expuestas hacia el exterior. Para el caso de la caravana ubicada en el "Chalet" (Porvenir), las ruedas quedan integradas en el interior del tabique pero cubiertas con el revestimiento exterior. A modo de excepción cabe señalar que la pieza de estancia "Lolita", en su revestimiento interior, la

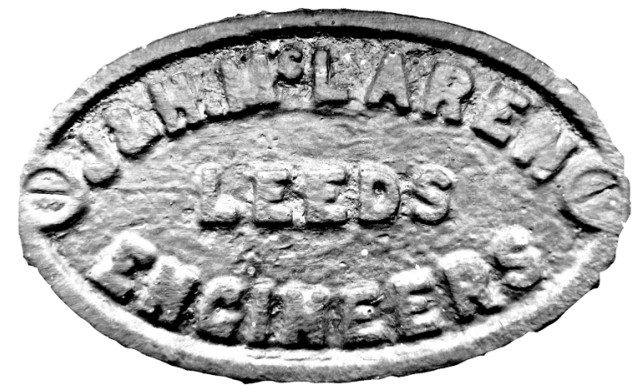

Fig. 5 Placa de fabricación de las caravanas $J \&$ M McLaren. tabiquería queda expuesta conformando un espacio de gran utilidad, pensado para el ordenamiento del atalaje $\mathrm{u}$ otros elementos domésticos (ver fig. $4 \mathrm{a}$, $4 \mathrm{c}, 4$ e). Por último y reflejo del ingenio humano, y ausencia de fabricantes de ruedas de madera, cabe señalar su reemplazo por ruedas de vehículos motorizados. Tales son los casos de las caravanas ubicadas en la estancia "Aurelia del Carmen" y "Dos Lagunas", asegurando de esta forma su durabilidad en el tiempo y favoreciendo su traslado (ver fig. 2h).

\section{COMENTARIOS FINALES}

La caravana, como un elemento patrimonial hoy estático, requiere de conservación y protección, en tanto que es parte del patrimonio identificatorio territorial sudpatagónico. Cabe, por ello, promover entre los operadores turísticos la valorización del turismo cultural que incluya las formas de economía pastoril y de una modalidad de vida campesina que ciertamente merecen ser conocidas y difundidas entre propios y extraños. En la actualidad algunas caravanas, que resistieron al paso del tiempo, son valoradas como registros de un tiempo pasado que es necesario conservar para la posteridad; son los casos de la estancia el "El Vukasovic", "El Morro", el "Chalet", hostería "Tres Pasos" (diseñada y construida con fines turísticos), "Cerro Guido" y "Laguna Amarga", donde actualmente las caravanas se exhiben como un atractivo turístico y como tal se agradece esta iniciativa en cuanto asegura su integridad en el tiempo.

Aun queda algo por conocer de las caravanas y en lo que más interesa del diario vivir de gente anónima en estos puestos de trabajos, ¿qué significaba vivir en una caravana, aislado y en soledad? Una impresión particular dejó el viajero Arturo Fuentes Rabé, luego de su viaje a comienzos de abril de 1918 por Tierra del Fuego: Triste, en verdad, es aquel lugar el [puesto] de destierro para los infelices que deben habitarlo. Solos en medio de la inmensidad espantosa de aquellos lugares solitarios, el alejamiento absoluto de centros poblados, y mas que nada, la época de frío intenso para la cual estaba destinada, hace que se mire aquel punto, como un lugar de expiación para los desheredados de la fortuna ${ }^{7}$. ¿Cómo se elegía a quien le tocaba habitar en el puesto? Era

$7 \quad$ Fuentes Rabé 1923: t.II, 41 
algo voluntario o que se imponía, es también una incógnita que solo podría aclararse ante el hallazgo de documentos escritos o fotográficos.

\section{AGRADECIMIENTOS}

Dejamos constancia de nuestros agradecimientos hacia Andrés Azua Sánchez y Daniela Peña Gatica por su colaboración en las salidas a terreno. También a Nicolás Recabarren Traub y a Macarena Fernández Génova por su gentileza y disponibilidad para brindarnos antecedentes acerca de las caravanas ubicadas en Puerto Yartou y puesto "Zapata" (estancia "Cameron").

\section{BIBLIOGRAFÍA}

Benavides, J. Martinic, M. Pizzi, M. \& Valenzuela, M. (1999). Las estancias magallánicas. Santiago: Editorial Universitaria.
Cascardo, A. (1983). La construcción rural pionera en Última Esperanza, fines del siglo XIX hasta 1905. En: Actas del primer congreso de Historia de Magallanes. Punta Arenas: Instituto de la Patagonia, Universidad de Magallanes.

Fuentes Rabé, A. (1923). Tierra del Fuego 2 t. Valdivia: Imprenta Central.

Lolich, L. (2003). Patagonia. Arquitectura de estancias. Buenos Aires: CEDODAL.

Mirelman, S. Lolich, L. \& Fernández, M. J. (2006). Arquitectura pionera de la Patagonia sur. Capítulos de la historia de Río Gallegos (18851940). Buenos Aires: Instituto Salesiano de Estudios Superiores.

Novoa, Z. (1982). Estancias Magallánicas. Seminario Facultad de Arquitectura y Urbanismo, Universidad de Chile: [s.e.].

Garcés, E. Kroger, F. Martinic, M. Piwonka, N. \& Cooper, M. (2013). Tierra del Fuego: Historia, Arquitectura y Territorio. ARQ, Santiago: Pontificia Universidad Católica de Chile. 